\title{
"Temos apaixonados para o mar e para a terra": representações do esporte nos folhetins (Rio de Janeiro; 1851-1855)
}

CDD. 20.ed. 796.08

Victor Andrade de MELO*
*Faculdade de Educação, Universidade Federal do Rio de Janeiro.

\section{Resumo}

Tendo em conta a relevância do material publicado nos primeiros folhetins brasileiros, olhares privilegiados sobre um momento importante da história do pais, o objetivo deste estudo é discutir a presença do esporte no Rio de Janeiro dos anos iniciais da segunda metade do século XIX (1851-1855) a partir das representações de três pioneiros da crônica brasileira: José Maria Paranhos, Francisco Otaviano e José de Alencar. Estimulou-nos um conjunto de pioneirismos que de forma alguma são ocasionais: os momentos iniciais de uma prática, representados nos primeiros instantes de um gênero literário, em um período em que havia certa estabilidade política e econômica, no qual, entre alguns grupos, se fortaleceu o desejo de adoção de um ideário moderno.

Palavras-chave: História do esporte; Literatura; Imprensa; Segundo Império.

\section{Introdução}

O objetivo deste estudo, uma pesquisa histórica, é discutir a presença do esporte no Rio de Janeiro dos anos iniciais da segunda metade do século XIX (18511855) a partir das representaçōes de três pioneiros da crônica brasileira: José Maria Paranhos, Francisco Otaviano e José de Alencar. Embora não centrais, também serão utilizadas algumas crônicas de Francisco Picot e Justiniano da Rocha, aquelas que deram sequência às séries dos dois primeiros cronistas, ocasião em que se buscou manter semelhantes estratégias de narração.

A relevância da utilização de crônicas como fontes para investigar o esporte já chamou a atenção de outros pesquisadores; só para ficar entre aqueles que trataram do tema no século XIX, podemos citar os estudos de Melo ${ }^{1-2}$ e LuCENA ${ }^{3}$. Esses, todavia, majoritariamente fizeram uso daquelas publicadas nas décadas finais do século XIX e iniciais do XX, quando, no Brasil, notadamente na capital, tanto o projeto de modernidade estava mais avançado quanto o campo esportivo encontrava-se mais consolidado. Os escritos com os quais trabalhamos neste artigo, ao revés, abordaram um instante em que a prática ainda era uma novidade, inserida em uma dinâmica social na qual se iniciavam as aspirações à modernidade.

Estimulou-nos esse conjunto de pioneirismos que de forma alguma são ocasionais: os momentos iniciais de uma prática (o esporte), representados nos primeiros instantes de um gênero literário (a crônica), em um período em que, entre certos grupos, se fortaleceu o desejo de adoção de um ideário moderno ${ }^{4-5}$.

"Temos apaixonados para o mar e para a terra": a frase, uma referência às regatas e corridas de cavalos realizadas no Rio de Janeiro, em 1851, é de autoria de Francisco Antônio PICOT ${ }^{6}$, um dos mais importantes jornalistas do século XIX, atuante no Jornal do Commercio desde 1834. Na condição de sócio (desde 1837) e diretor geral (1844 a 1890) desse periódico, foi um dos responsáveis por criar, em 1852, a primeira seção de um jornal brasileiro denominada "Folhetim".

Folhetim, segundo a definição de Maria do Socorro Nóbrega ${ }^{7}$, é:

um espaço tipográfico, no pé da página de jornal, que, por metonímia, se transformou em tipo de texto: qualquer escrito que ali aparece poder ser referido como "Folhetim". No caso do folhetim de imprensa, tem-se um conjunto de blocos de textos, justapostos, separados e numerados com algarismos romanos, correspondendo cada qual a narrativas autônomas (p.1).

Essa seçāo dos jornais surgiu na França, nas décadas finais do século XVIII, e foi se diversificando no decorrer do tempo: em alguns casos, era dedicada 
à crítica teatral ou de artes; em outros, à publicação seriada de romances. Nela, veiculavam-se também escritos dedicados a narrar o cotidiano das cidades, em tom menos formal, buscando-se maior intimidade com o leitor ${ }^{7}$. Nesse último caso, estamos a falar da gestação da crônica enquanto um gênero literário específico.

Nos jornais brasileiros, ainda que, como vimos, só em 1852 tenha surgido uma seção denominada "Folhetim", percebe-se a existência de espaço semelhante já na década de 1820: o Jornal do Commercio, desde o seu primeiro número (outubro de 1827), reservava o "pé de página" para divulgar as notícias de eventos artísticos". SOARES ${ }^{8}$ lembra que as seçōes "Apêndice" (1831), de O Moderador, Novo Correio do Brasila, e "Folha" (1836), de O Cronistab, também apresentavam características de um folhetim. Destaca ainda "A semana lírica", de Martins Pena, dedicada ao teatro, publicada de agosto de 1846 a setembro de 1847, no Jornal do Commercioc.

No que se refere ao uso do espaço para a publicação de romances, para $\mathrm{NADAF}^{9}$, o primeiro folhetim literário veiculado no Brasil teria sido o de Paul de Kock: "Edmundo e sua prima", no Jornal do Commercio, em 1839. Nesse mesmo ano, Justiniano José da Rocha publicou, no mesmo periódico, "A paixão dos diamantes”, de clara inspiração europeia. No decorrer do século XIX, importantes literatos brasileiros fizeram o mesmo ${ }^{\text {d: }}$ "A imprensa teve importância capital para os que aspiravam viver das letras no Brasil do século XIX, uma vez que o jornal atingia um número cada vez maior de leitores, possibilitando o acesso à popularidade"10 (p.124).

O que se pode perceber, de fato, é o que IPANEMA ${ }^{11}$ chama de "interpenetração dos conceitos": notícias cotidianas, mais ao modo das crônicas, e romances conviviam na mesma seção, sob responsabilidade de autores distintos, publicados em diferentes dias da semana.

Entre os que pioneiramente publicaram crônicas nos jornais brasileiros, três dos mais importantes abordaram o esporte: José Maria da Silva Paranhos (o futuro Visconde do Rio Branco), Francisco Otaviano de Almeida Rosa e José Martiniano de Alencar, os dois primeiros no Jornal do Commercio $^{\mathrm{e}}$ e o último no Correio Mercantilt.

José Maria Paranhos é originário da Bahia (nasceu em 1819). Chegou ao Rio de Janeiro, na década de 1830, para realizar estudos na Escola de Marinha e na Escola Militar, de onde se tornou professor. Desde os anos 1840, esteve envolvido com a imprensa, que serviu de trampolim inicial para uma brilhante carreira política e diplomática. A princípio ligado ao Partido Liberal (pelo qual, em 1845, foi eleito deputado da Assembleia do Rio de Janeiro), depois de passar para o Partido Conservador tornou-se um dos principais estadistas do Segundo Reinado. Ocupou postos-chave e se envolveu com importantes acontecimentos do Impériog.

Em 1850, Paranhos entrou para o Jornal do Commercio, onde atuou como redator e publicou, a partir de 23 de dezembro, de forma anônima, na seção "Comunicados", a série "Ao Amigo Ausente": semanalmente, como se estivera escrevendo uma carta, comentava os principais acontecimentos do país, especialmente o que ocorria na sociedade da Corte. Manteve-se responsável por essa seção até 18 de outubro de $1851^{\mathrm{h}}$, quando, por motivos de serviço diplomático, viajou para o Uruguaii.

Muitos pesquisadores não consideram esses escritos como o início da crônica brasileira, reconhecendo como pioneiro Francisco Otaviano, que, entre dezembro de 1852 e julho de 1854, escreveu a série "A semana", na seção "Folhetim do Jornal do Commercio", fazendo uso de "procedimentos narrativos até então inéditos"

Contudo, se tivermos em conta as características do gênero literário, conforme hoje concebemos, inegavelmente a atuação de Paranhos pode ser considerada como exemplo de um cronista em ação ${ }^{j}$, inclusive porque o autor descrevia, com cumplicidade com o leitor, o que vivenciava e acompanhava tanto na política quanto na vida social: "Paranhos participava de todas as festas, frequentava o Prado, adorava os bailes e recomendava sempre aos que o escutavam que gozassem o mundo, porque fugaces labuntur anni"12 (p.xviii).

De qualquer forma, é inegável a importância de Francisco Otaviano, que, como Paranhos, teve uma notável carreira política e diplomática, tendo ocupado importantes postos no Impériok. Originário do Rio de Janeiro (nasceu em 1825), formado em Direito (pela Escola de São Paulo), esteve envolvido com a imprensa desde meados da década de 1840: também, para ele, tal atuação foi importante para alavancar sua trajetória profissional.

Em 1854, Otaviano transferiu-se para o Correio Mercantil, para assumir uma função de direção. Para seu lugar indicou um antigo colega da Escola de Direito: o cearense José de Alencar. A diretoria do Jornal do Commercio, contudo, preferiu entregar a seção "Folhetim" para Justiniano José da Rocha, que já possuía maior experiência jornalístical. Otaviano, então, convidou Alencar para ficar responsável pelas "Páginas Menores", o folhetim do seu novo jornal. Foi nesse espaço que o literato publicou a série "Ao correr da pena", entre setembro de 1854 e julho de $1855^{\mathrm{m}}$. 
Ainda mais do que Paranhos e Otaviano, Alencar, que futuramente ocuparia espaço de honra na literatura brasileira, se dirigia com cumplicidade para seus leitores, elegendo as elites como interlocutores principais. De outro lado, exerce mais contundentemente a verve crítica, não se furtando a se envolver em polêmicas sobre os mais diferentes temas.

Há que se ter em conta o momento em que esses personagens escreveram. $\mathrm{Na}$ ocasião, segundo os dados do Almanak LAemmerT ${ }^{13}$, o Brasil tinha em torno de cinco milhões e 500 mil habitantes; pouco mais de 250.000 viviam no município da Corte (cerca de 110.000 escravos) ${ }^{\mathrm{n}}$.

Depois de três décadas de instabilidade econômica e política, o país encontrava melhores condiçōes para se consolidar enquanto uma nação. Discutia-se mais profundamente suas instituiçōes e seu futuro. Começa-se a construir um projeto de modernidade sustentado por uma sensação de progresso e bemestar material, mais bem perceptível entre as elites. São grandes os debates e as reformas planejadas em curto espaço de tempo ${ }^{14-15}$.

Do ponto de vista político, as casas parlamentares e o ministério eram claramente conservadores, mas havia uma relativa trégua entre o Partido Liberal (mais ligado aos setores urbanos e comerciais) e o Partido Conservador (mais ligado aos donos de escravos), deixando para trás, pelo menos momentaneamente, as turbulências das décadas anteriores ${ }^{\circ}$.

No cenário econômico, foi um período de estabilidade financeira, sustentada por um bom momento na agricultura, especialmente do café. Além disso, deu-se o tímido início de um processo de diversificação econômica, com o lançamento das primeiras bases da industrialização, relacionada não só à expansão ferroviária, que ligava áreas de produção agrícola, como também à necessidade de melhoria das condições de vida da população, notadamente no que se refere a investimentos na infraestrutura urbana ${ }^{5,15}$.

No aspecto cultural, percebe-se, notadamente na capital, um aumento do trânsito de mercadorias e de costumes do mundo "civilizado" europeu, até mesmo em função do incremento da navegação a vapor para o velho continente 5 . Uma das decorrências desse processo foi o desenvolvimento de uma maior disposição para a ocupação do espaço público como "lócus" de encontros.

$\mathrm{Na}$ mesma medida, aumentou a preocupação com o controle urbano e com a eliminação de práticas consideradas bárbaras e ultrapassadas. Como infere RODRIGUES ${ }^{12}$ : era uma sociedade que se transformava, que alterava seus hábitos e estilos, que se apurava, romantizava, esmerava-se, acompanhando, num novo ímpeto de criação de valores espirituais, os impulsos da estrutura econômica abalada e revolucionada nas suas raízes mais profundas (p.xxxv).

Assim, no Rio de Janeiro, tratou-se de um período marcado pela valorização dos divertimentos, destacando-se o teatro, os bailes, as festas religiosas, os salōes, os passeios e uma novidade: o esporte.

Nossos cronistas, de diferentes pontos de vista, estiveram engajados na defesa do avanço social, do progresso do país. Por seus escritos desfilam as tensões e ambiguidades desse processo de transição, suas interpretações e críticas sobre o que ocorria em uma sociedade em ebulição; seus projetos e propostas para o presente e para o futuro:

A crônica folhetinesca, que acaba se tornando um estilo literário, nos fornece uma "historicizaçáo" do cotidiano carioca. A sociabilidade transparece na escrita do comentário semanal que, em muitos momentos, lembra o romance-folhetim que já é publicado em capítulos no rodapé do jornal. A vida na cidade do Rio de Janeiro narrada em fragmentos nos rodapés registram, representam, constroem e divulgam ideias e valores de uma realidade e se constituem como um discurso que expressa um "tempo social"16 (p.6).

A despeito das diferenças de estilo e de perspectivas de cada autor, os assuntos abordados eram muito semelhantes: mesclavam-se temas "sérios" da vida política e econômica da nação (por exemplo, o tráfico de escravos, as primeiras iniciativas de industrialização, os conflitos relacionados à política externa), com questóes cotidianas que preocupavam a sociedade (a limpeza urbana, a violência das cidades, o transporte público, os problemas com a saúde) e comentários sobre a "vida mundana" (a moda, os divertimentos, os novos costumes).

Como bem define José de Alencar, tratava-se de "percorrer todos os acontecimentos, passar do gracejo ao assunto sério, do riso e do prazer às páginas douradas do seu álbum". Para ele, nesse sentido, o cronista era "uma espécie de colibri a esvoaçar em ziguezague, e a sugar, como o mel das flores, a graça, o sal e o espírito que deve necessariamente descobrir no fato o mais comezinho!"17.

Tais crônicas, assim, podem revelar-se fontes relevantes para se lançar um olhar sobre um período importante da história brasileira, especialmente da capital. Não se trata de nelas buscar uma "pura expressão" da verdade, mas sim as representaçōes construídas por personagens privilegiados que agiram como mediadores entre diferentes grupos. 


\section{Que esporte?}

Os cronistas investigados registraram os primeiros momentos de uma das modalidades que pioneiramente se institucionalizou no Rio de Janeiro: o turfe. Corridas de cavalos, de forma não contínua, eram realizadas na capital desde a década de 1810 , normalmente na Praia da Saudade, em Botafogo. Há registros de provas realizadas em 1814, 1816, 1825, 1847; em 1849 é criada a primeira agremiação dedicada à prática, o Club de Corridas, que, todavia, só promoveu uma atividade, em 1850, em um hipódromo construído na região do Engenho Novo, o Prado Fluminense ${ }^{p}$.

Em 1851, um dos fundadores do Club, João Guilherme Suckow, prussiano que chegara ao Rio contratado para integrar o Exército Brasileiro e se envolvera com empresas ligadas ao aluguel de carruagens e cavalos, arrenda o Prado e promove uma série de benefícios com o intuito de oferecer corridas frequentes.

Paranhos acompanha o momento que antecede as primeiras provas por Suckow organizadas, descrevendo claramente as mudanças pelas quais passava o hipódromo sob sua direção:

O novo empresário desses exercícios tomou o Prado por oito anos. Obrigou-se a levantar um edifício de dois andares para bem-estar dos espectadores e tenciona dar quatro corridas por ano. A primeira provavelmente terá lugar pelo Espírito Santo, embora não haja para esse tempo mais do que uma arquibancada provisória. Consta-me que nos domingos à tarde será o Prado franqueado gratuitamente a cavaleiros, ou como ponto de reunião, ou para corridas particulares ${ }^{18}$.

O cronista manteve os leitores atualizados acerca dos preparativos, semana após semana narrando todos os detalhes: a reforma das instalaçôes (arquibancadas, restaurante, pista de corrida), a organização do programa, as expectativas de receber bom público. Mais ainda, reivindicava apoios para que tudo saísse da melhor forma:

a quem de direito for que olhe para os dois caminhos que conduzem ao Prado Fluminense, que se acham no mais deplorável estado. O que vai direito ao portão, e que ofereceria um lindo passeio, achase inteiramente intransitável desde o ponto de uma chácara pertencente à sra. Condessa de Sarapuí até à chácara do Sr. Carneiro. O segundo caminho, que é o do Pedregulho, quem o quiser atravessar de carro ou a cavalo, se tiver bom senso, deve antes fazer o seu testamento ${ }^{19}$.

Era explícito o seu desejo de que a iniciativa lograsse sucesso:
O divertimento das corridas de que falei na minha última carta, creio que será muito agradável e concorrido. (...). Os empresários têm tomado todas as necessárias precauçôes para que os espectadores possam gozar do espetáculo, ainda bem pouco visto e apreciado entre nós ${ }^{19}$.

Duas semanas antes das provas inaugurais, previstas para 13 de junho, Paranhos mal contém seu animo: "Ver de dia umas poucas carreiras de cavalos, e à noite festejar o milagroso Santo Antônio com bichas e traques da Índia, é uma verdadeira bem-aventurança terrestre, para a qual espero que Deus me não inabilitará" ${ }^{20}$. Segundo seu olhar, a expectativa pública teria chegado a tal ponto que desencadeara uma avidez por informaçōes:

uns querem saber se será um espetáculo franco onde reinem fraternité, liberte et egalité, outros perguntam se, ao modo dos benefícios, les entrées de faveur sont généralement suspendues, se a gente irá a pé ou a cavalo, se haverá gôndolas e ônibus, se haverá lugar para as ornejantes criaturas, ou se estas farão de espectadores promiscuamente com os bípedes, se o sexo amável será admitido, e com que regalias, e ultimamente se poderão ali mesmo pagarem-se as letras do estômago que não admitem reforma de prazo ${ }^{21}$.

O olhar de Paranhos permite-nos perceber tanto o possível interesse público que cercava a novidade, notadamente por parte de gente da elite (pelo menos as perguntas do cronista eram mais afeitas a esse estrato social), quanto o desconhecimento acerca do que se passaria no Prado, servindo o seu escrito como instância pedagógica, uma função que desempenhará a imprensa constantemente. O cronista, para melhor esclarecer o leitor, e matar sua própria curiosidade, consulta diretamente Suckow, dele recolhendo uma descrição do que vai ocorrer e as garantias de que as corridas a ninguém decepcionariam.

$\mathrm{Na}$ crônica seguinte à tão esperada inauguração, que contou com a presença das mais importantes personagens da sociedade carioca, inclusive a família imperial, Paranhos sacramenta: "O sucesso mais notável desta semana foi o que ontem teve lugar no Prado Fluminense em presença de perto de quatro mil pessoas de diversos sexos, gêneros e espécies" 22 . Ao narrar com detalhes o ocorrido, o cronista deixa clara sua posição sobre a importância do turfe: tratase de um sinal de que o país civiliza-se.

Seu posicionamento sobre o evento seguinte é da mesma forma entusiasmado: "Houve no domingo passado novas corridas de cavalos no Prado 
Fluminense. O concurso foi desta vez maior do que no primeiro divertimento equestre com que o Sr. Major Suckow nos obsequiou este ano"23. Mais ainda, Paranhos sugere que o público paulatinamente ia aprendendo a dinâmica do espetáculo e tornandose cada vez mais presente e ativo.

Um dos aspectos interessantes dessas crônicas é a informação do nome dos personagens envolvidos com os primeiros eventos turfísticos. Aos jóqueis não se dava muita atenção; eram, em geral, afinal, como dizia Paranhos, "todos caboclos ou com eles parecidos" 22 . Já os cavalos e os proprietários eram sempre citados. Por exemplo, entre os donos de animais inscritos nas provas inaugurais do Prado podemos destacar: James Hudson, diplomata britânico no Brasil, na ocasião embaixador, um dos mais envolvidos com o cumprimento do tratado que determinou o fim do tráfico negreiro; Luís R. de Souza Rezende, engenheiro de prática, futuro industrial e capitão na Guerra do Paraguai; Cândido Ferreira, importante negociante, na época presidente da Associação Comercial do Rio de Janeiro.

Esse é o perfil dos que participaram das primeiras iniciativas de estruturação do turfe fluminense: inicialmente eram os que estavam envolvidos com projetos de modernização da cidadeq; posteriormente também aderiram aristocratas ligados à cafeicultura. A composição dos clubes de corridas de cavalos, de fato, durante muitos anos, foi uma expressão das tensões, composiçōes e hibridações das classes dirigentes brasileiras. NEEDELL ${ }^{24}$ capta bem esse aspecto ao referir-se ao Jockey Club: "Talvez a instituição tenha conseguido manter o patrocínio da elite e o vigor financeiro porque se mostrou bastante flexível às sucessivas mudanças no gosto e na composição das elites" (p.100).

Outro aspecto interessante é perceber que os eventos turfísticos ainda não tinham um formato único; durante muitos anos várias experiências foram realizadas tendo em vista atrair o público. Nos anos 1850, destacam-se as corridas informais que ocorriam entre as provas do programa oficial: cavalos conduzidos não por jóqueis contratados, mas sim por "gentlemen riders", voluntários que se apresentavam para disputar uma ou outra carreira.

Vemos um exemplo desse tipo de disputa na crônica de Francisco Otaviano em que narra um evento organizado no Prado, em 8 dezembro de 1851. A corrida dos amadores foi vencida por um Sr. Carvalho, um estudante de medicina que praticava constantemente o turfe como "exercício higiênico" e foi efusivamente saudado pelo público ${ }^{25}$.
Nessa mesma crônica, aliás, lança-se um debate que perseguirá o turfe por muitos anos: um menino chamado Balbino ganhara seis corridas, levando Otaviano a questionar a adequação da escolha de uma criança como jóquei. A preocupação não se relacionava exatamente com a integridade infantil, mas sim com a justiça dos resultados, já que era muito leve o condutor.

Como nos escritos de Paranhos, é rica e minuciosa a descrição de Otaviano das corridas de cavalos; é, na verdade, ainda mais empolgada. Seu intuito era narrar da melhor forma possível o frenesi observável ao redor da nova atividade, pela qual tanto demonstrava simpatia por ser uma expressão dos novos tempos:

Correi, correi, bravos mancebos! - Quem aposta pelo

jockey escarlate e preto, que eu aposto pelo de gibão verde? - Um bilhete de loteria pelo gancho. - Topo e dobro a parada pelo picaço. - Lá vai ele. - Não: é o verde que vence. - Aí! Que se atrasou na curva: viva o escarlate e preto! - Ei-los que aí vem assim, assim: bravo o jockey! Bravo o animal! Hurrah! Venceu o escarlate: e a música atroa os ares e o povo aplaude, e as senhoras acenam com os lenços, e o cavaleiro salta do animal, e os juízes o proclamam vencedor ${ }^{26}$.

A despeito de seu entusiasmo, Otaviano escreve em um momento em que o turfe ainda dava passos claudicantes. Nas suas crônicas vemos, por exemplo, o anúncio do surgimento de uma nova agremiação, o Jockey-Club Fluminense. Longe de ser motivo de grande comemoração, o novo clube foi criado porque Suckow, não podendo mais arcar sozinho com os custos de manutenção do Prado, tentou uma vez mais ampliar o número de associados envolvidos (como o fora a pioneira, e de pouco sucesso, experiência do Club de Corridas). Perspectivava-se também a organização de provas que prescindissem de jóqueis contratados, uma iniciativa que poderia, ao mesmo tempo, contribuir para baixar os custos e elitizar a prática:

já se reuniram sexta-feira em casa do Dr. A. da Costa muitas pessoas de distinção, e fundaram um Jockey-Club sob a presidência do Sr. coronel Polydoro, comandante do corpo municipal desta cidade. $\mathrm{O} c l u b$ tenciona promover em épocas fixas corridas brilhantes somente de gentlemen riders. Como o primeiro gentlemen do império é S.M. o Imperador acredita-se que ele se dignará de aceitar o protetorado da associaçãa ${ }^{26}$.

A atividade inaugural da nova sociedade merecerá referência no "Folhetim do Jornal do Commercio", àquela altura já não mais sob responsabilidade de Otaviano, que se transferira para o Correio Mercantil. É seu substituto, Justiniano da Rocha, que registrou: 
"basta dizer-vos que nunca mais belo concurso expôs à implacável poeira semblantes mais risonhos, mais animados, neste nosso Rio de Janeiro, pátria adotiva de todas as elegâncias" ${ }^{26}$ (p.1).

Se o novo cronista saúda de forma enfática a prática, uma peculiaridade merece observação. Enquanto para Paranhos e Otaviano a estruturação do turfe apontava para um projeto de futuro, para Rocha estabelecia uma ponte com o passado, uma possibilidade de preservação de algo que começa a ser apagado pelo progresso:

nos dias em que vivemos a máquina de vapor, esse monstro que se alimenta de carvão e de labareda, vai matando o cavalo; se os divertimentos hípicos o não conservarem, o não transmitiriam à notoriedade, quem sabe se nossos netos não acreditarão que a palavra cavalo, em vez de indicar um ente vivo, garboso, e útil, uma das belezas do reino animal, apenas servia para indicar a unidade na medida da força, como a palavra metrominica a unidade de medida da extensão? Poupemos aos nossos netos essa lamentável ignorância; guardemos-lhes algumas amostras do cavalo-bicho; e pois, quanto aos divertimentos hípicos, viva o Jockey-Club, viva o major Suckow, a cuja perseverança devemos mais essa importação; vivam e revivam todos esses que afrontam, para ir ao Prado, o calor e a poeira (... $)^{27}$ (p.1).

As provas inaugurais do Jockey Club mereceram também a atenção de José de Alencar. Se sua narração ia ao encontro da de Paranhos e Otaviano no que se refere à movimentação do público, ele era, contudo, bem mais crítico. Vejamos, por exemplo, sua descrição do Prado:

Tudo isso lutando de entusiasmo e ligeireza, turbilhonando entre nuvens de pó, animando-se com a excitação da carreira, formava uma confusão magnífica; e passava no meio dos estalos dos chicotes, dos gritos dos cocheiros, do rodar das carruagens, e do rir e vozear dos cavaleiros, como uma espécie de sabat de feiticeiras, a começar no campo de Sant'Anna e a perder-se por baixo da sombra de meia dúzia de árvores do Prado e das tábuas sujas e carcomidas de uma barraca que por capricho chamam pavilhão, e que de velha já se está rindo das misérias do mundo ${ }^{17}$. A crítica não se restringia às instalações. Também os jóqueis, cavalos e tudo o mais não passam incólumes ao olhar de Alencar:

Às 10 horas abriu-se a raia $(t u r f)$, e começou a corrida com a irregularidade de costume. Os parelheiros pouco adestrados, sem o ensino conveniente, não partiram ao sinal e ao mesmo tempo, e disto resultou que muitas vezes o prêmio da vitória não coube ao jóquei que montava o melhor corredor, e sim àquele que tinha a felicidade de ser o primeiro a lançar-se na raia. A última corrida, que durou um minuto e dezenove segundos, teria sido brilhante se dois dos cavalos não se tivessem lembrado de imitar as pombinhas de Vênus, que dizem, voavam presas por um laço de amor ${ }^{17}$.

A posição de Alencar faz jus a sua fama de polemista. De qualquer forma, efetivamente a nova agremiação não teve vida longa. Os prejuízos acumulados e a queda do interesse do público levaram a sua extinção após ter sido realizado um único evento. Somente na década de 1860 uma nova iniciativa teria mais sucesso no intuito de consolidar o turfe nacional: a criação do Jockey Club, em 1868, que usou, até os anos 1920, as mesmas instalações do velho Prado do Engenho Novo.

Outra modalidade registrada pelos autores investigados foi o remo. As regatas, todavia, ocuparam espaço significativamente menor em suas crônicas. De fato, na ocasião tratava-se de uma prática menos estruturada do que o turfe, ainda enfrentando muitas restrições para seu pleno desenvolvimento, notadamente no âmbito dos costumes.

Nas crônicas de Paranhos percebemos uma dessas restrições, a principal delas: as preocupações com o pudor, que obliteravam a possibilidade de uma ocupação mais despojada das praias como alternativa de diversão. Vejamos como o autor celebra as "flutuantes", barcas instaladas no mar, na altura do Hotel Pharoux (que se localizava nas cercanias da atual Praça XV, centro da cidade), para oferecer a alternativa de acesso aos banhos ${ }^{\mathrm{t}}$ :

Ainda não anunciei uma excelente comodidade de que há tempos goza a população do Rio de Janeiro, e que fez progressos do ano passado para cá. Para tomar banhos de água salgada, não é preciso mudar de casa, abarracar nas praias, ou expor-se às vistas dos curiosos ${ }^{28}$.

É minuciosa a descrição do estabelecimento. Ficamos sabendo que havia muito conforto para os que desejavam desfrutar do contato com a água do mar, que corria em banheiras disponíveis em camarotes reservados e limpos, ou "respirar um ar livre, gozar a vista do porto, e ouvir harmoniosos sons de um piano, que não cessa de gemer e cantar, para distrair os seus ouvintes" 28 .

As regatas, de fato, não foram citadas nas crônicas de Paranhos, muito provavelmente não por qualquer tipo de restrição por parte do autor, mas pelo fato de não ter ocorrido alguma prova náutica no tempo em que esteve à frente da seção. Já Francisco Picot, responsável por dar sequência às "Cartas ao amigo ausente", não as deixou passar em branco em seu escrito de 3 de novembro de 1851. Aliás, as descreve em um dia em que aconteceram simultaneamente a provas de turfe: 
Estou indeciso; estão anunciadas para as 3 horas a regata e a corrida de cavalos, aquela no mar de Botafogo, esta no Prado Fluminense, que fica lá para banda do Engenho Novo. Para onde irei? Se não tivera tanta vontade e necessidade de divertirme, decidiria a questão peremptoriamente; não iria nem a Botafogo, nem ao Engenho Novo ${ }^{6}$.

Picot opta pelas regatas, vislumbrando a possibilidade de ser convidado para alguma das muitas festas que se seguiriam às provas, mais especificamente para $\mathrm{O}$ baile que o Visconde de Abrantes ${ }^{\mathrm{u}}$ ofereceria em uma embarcação. Aparentemente, tanto quanto as corridas de cavalos, as atividades náuticas atraiam muito público: "Chego a Botafogo: são 3 horas da tarde, tudo respira festa e prazer. Não há uma janela vazia, a praia está cheia de espectadores, o mar coalhado de pequenas embarcações de todas as formas e feitios" "v6.

A crer na posição irônica de outro cronista, Justiniano da Rochaw ${ }^{\mathrm{w}}$, as regatas eram mesmo aguardadas com expectativa pela população:

Regata. Quinta-feira não houve páreo no Botafogo; mas juro que houve regata nas ruas de toda a cidade. A regata da quinta-feira foi da chuva, que logrou a mais de quatro; a dos boles ficou adiada para segunda-feira 21 do corrente; assim mesmo houve na praia de Botafogo na tarde daquele dia povo como formiga; não me posso admirar de que tanta gente saísse de casa, apesar da chuva, quando no domingo à noite a rua da Vala ficou cheia de mulheres por causa do fogo ${ }^{29}$.

Pela crônica de Picot ficamos sabendo que tomavam parte na organização das provas militares de alta patente da Marinha de Guerra, como Joaquim Marques Lisboa (o futuro Almirante Tamandaré), Francisco Manoel Barroso (futuramente almirante e herói na Guerra do Paraguai) e Roberto Grundy (engenheiro chefe da Armada).

A Armada fez-se presente de diversas formas: marinheiros de baixa patente conduziram embarcações, oficiais integraram equipes, houve provas entre distintos setores da Marinha, realizaram-se disputas entre as tripulações de navios de diferentes países. Houve, de fato, muitos estrangeiros competindo nos páreos.

O que Picot e Rocha captam são as primeiras tentativas mais estruturadas de promoção de regatas na Enseada de Botafogo e na Praia do Caju, realizadas depois dos desafios informais que com frequência vinham ocorrendo no Rio de Janeiro desde os anos finais da década de $1840^{\mathrm{x}}$. Mesmo que melhor organizadas as competições, não havia ainda, contudo, os clubes, que só surgiriam a partir da década de 1860 , quando estariam semeadas condições mais concretas para o desenvolvimento do esporte náutico (que só se consolida na transição dos séculos XIX e XX).

As regatas estiveram também presentes nas crônicas de José de Alencar. No seu modo de entender, compunham adequadamente o belo quadro que se tornara comum em Botafogo, "o rendez-vous da sociedade elegante":

Quanta coisa bonita que se prepara este tempo!

Que belas noites, que alegres divertimentos nos promete ainda o arrabalde do Botafogo! Uma regata, um baile popular, e um fogo de artifício suspenso sobre as águas límpidas da baía! Que magnífico espetáculo! A minha pena, coitadinha, já está tremendo de susto, só com a ideia de que há de ser obrigada a descrever todas essas maravilhas ${ }^{30}$.

Ainda que empolgado com as provas náuticas, assim como ocorrera com o turfe, o cronista mantinha uma relação de certa distância. Por exemplo, ao comentar uma regata realizada em maio de 1855 , se de um lado exercita sua veia romântica para valorizar a prática, afirmando que "apenas o mar, como um leão selvagem, eriçava a juba, estorcia-se furioso, e arrojava-se bramindo sobre as areias da praia”, de outro lado zomba dessa representação:

Isto, em bom português, quer dizer que havia uma ressaca insuportável. Mas é necessário recorrer de vez em quando às imagens poéticas, e seguir os preceitos da arte; e foi por isso que dei ao mar a honra de compará-lo a um leão selvagem e indômito. $\mathrm{Na}$ minha opinião, ele não passa de um sujeito muito malcriado, que, apesar de tanta moça bonita que se incomodou para ir vê-lo, pôs-se a fazer bravatas, como se alguém cá da terra tivesse medo dele ${ }^{31}$.

$\mathrm{Na}$ verdade, a regata em si passa ao largo de seus comentários, mais destinados a descrever o salão de Teixeira Leite, onde foram servidas comidas e bebidas de qualidade, motivo para o cronista desandar a falar sobre gastronomia. $\mathrm{O}$ que lhe interessava mesmo era a diversão. 


\section{Uma diversão útil}

Prossiga o Sr. Major Suckow no seu empenho, (...) e caber-lhe-á a satisfação de instituir no Rio de Janeiro um divertimento popular e de utilidade ${ }^{23}$.

Um dos temas mais constantes nas crônicas dos anos 1850/1855 foi a nova dinâmica pública das diversões. Tornaram-se tão relevantes os divertimentos para certos grupos, quase uma obrigação para os que desejavam ser reconhecidos nos mais altos círculos sociais, que José de Alencar ironicamente clama por uma reestruturação da semana de trabalho, em um momento em que efetivamente a sociedade carioca, até mesmo em função da diversificação econômica, começa a ter uma preocupação maior com o controle de tempo ${ }^{y}$ :

Se os antigos, que não tinham baile, nem teatros líricos, nem concertos, nem clubes, nem corridas, e que se contentavam com algum sarau de vez em quando, inventaram os dias santos para filarem assim dois dias de descanso, nós, que temos durante a semana todo esse enorme acréscimo de trabalho imposto pela sociedade, nós que já fomos privados dos dias santos, devemos em todo o rigor da justiça lograr mais um dia de descanso, e juntar a terça-feira à segunda, a fim de poder na quinta encerrar o trabalho, com o espírito calmo e o corpo bem disposto ${ }^{32}$.

Paranhos era o que narrava com mais entusiasmo uma das atividades mais apreciadas na cidade de então, os bailes, oferecidos pelos primeiros clubes recreativos que se organizaram na cidade:

São numerosas as sociedades de baile, de dança, musicais e dramáticas que atualmente existem no Rio de Janeiro. Aí vão os títulos das que neste momento me lembram. Sociedades de baile: Cassino Fluminense, Cassino da Floresta, Recreação Campestre, Recreação Brasileira, Terpsícore, Lísia, Paraíso, Ulisséa, Sílfide, Nova Eleusina, Vestal, Fidelidade, Filo-Euterpe, Assembleia Familiar Fluminense e Amante do Recreio ${ }^{33}$.

Descrevendo com detalhes as festas dançantes, que frequentava junto com a "mais fina flor da sociedade carioca”, Paranhos chegou, certa feita, a afirmar sobre um evento promovido pela Sociedade Recreação Campestre: "Foi, no meu sentir, o mais importante acontecimento da semana" 34 . Em outra ocasião é até mais enfático: "O baile! $\mathrm{O}$ baile é sempre o baile! Estas interjeições exprimem as mais sérias preocupaçōes, os mais vivos e afetuosos sentimentos da atual sociedade fluminense"23.

Para Paranhos, tais atividades eram uma expressão de uma nova forma de relacionamentos sociais, segundo seu olhar "mais democráticos", menos marcados pelos "constrangimentos da tirânica etiqueta” ${ }^{4}$. Melhor definindo: “Todas as classes aí estão representadas - as artes, as letras, a indústria, a lavoura e o comércio; o funcionário civil e o militar, grandes e pequenos, a inteligência e o dinheiro, o talento e a felicidade, o nacional e o estrangeiro" 23 . Obviamente o cronista se refere às elites, que adotam costumes mais distendidos, frutos, inclusive, dos mais frequentes contatos na esfera pública.

Otaviano não é tão entusiasta quanto Paranhos, mas também não deixa de reconhecer a importância dos bailes, para ele tão complexos, um "resumo de todas as ciências e artes" ${ }^{19}$, que para descrevê-los bem só se houvesse um "bailólogo". Já Alencar não perde a oportunidade de, junto com o registro do gosto social por tais encontros, fazer uma sutil crítica:

Começa a estação dos bailes e dos saraus. O Campestre dá a sua primeira partida por estes dias; o Cassino nos promete uma bela noite antes do fim do mês. Teremos naturalmente, como nos anos passados, uma febre dançante. Ninguém escapará à epidemia; e até alguns malévolos espelham que o próprio ministério fará uma contradança ${ }^{30}$.

Junto com os bailes e o teatro, assunto também comum nos escritos dos cronistas investigados, o esporte era celebrado como uma forma de diversão adequada aos novos tempos: civilizada e mais "democrática”. Paranhos, ao narrar a prova inaugural do clube de Suckow, comenta:

Festa do Espírito Santo da Lapa e no histórico campo da Aclamação, com música todas as noites, leilóes, barracas, e dois fogos de triques-traques, eram já por si causa mais que suficiente para agitar todo o oceano popular, quanto mais aparecendo um novo e estranho elemento, correrias equestres! $!^{22}$.

Francisco Otaviano também vê o turfe como uma das práticas que poderia salvar a sociedade do tédio. $\mathrm{O}$ problema, no seu olhar, é que o público nem sempre demonstrava suficiente interesse no esporte em si. Ao comentar o que considerou "as corridas mais notáveis que tem havido desde a instituição do clube" 35 , observa que: "Mas, ou por efeito do calor, ou por natural indiferentismo, não havia animação da parte da plateia, apesar de ter concorrido muita gente ao Prado" 35 . Para ele, as pessoas iam ao hipódromo mais para "se mostrarem, ou namorarem, ou conversarem" 35 .

$\mathrm{O}$ que mais interessava a um setor da sociedade, "as senhoras mais distintas e formosas, a rapaziada mais folgazona e espirituosa" 36 , era mesmo encontrar o mundo "fashionable" carioca. Otaviano capta, 
aliás, uma novidade que será uma das marcas do esporte em sua trajetória no país: a grande presença de mulheres, expressão tanto das reivindicações femininas por maior protagonismo social quanto das "concessões" masculinas frente à impossibilidade de mantê-las restrita ao espaço da casa. Mesmo que elas fossem cercadas de cuidados e restrições, logo as arquibancadas viraram lugar de flerte, até mesmo porque se tornou um espaço para a promoção de casamentos que interessavam à dinâmica política e econômica das famílias das elites².

Com tantas novidades no que se refere à ocupação dos espaços públicos, uma tônica nos escritos de nossos cronistas, especialmente nos de José de Alencar, era a necessidade de as autoridades manterem controle sobre as diversões, evitando as "turbas populares" e garantindo o aspecto "civilizado" da capital. Na verdade, sugere-se que as próprias elites deveriam ser educadas para assumir gestos e comportamentos mais refinados e condizentes com sua responsabilidade social. Criticavam-se antigos hábitos, valorizavam-se novas práticas.

Ainda assim, ambiguidades são perceptíveis em suas posiçōes. Por vezes percebiam-se demonstraçōes de irritação com o rigor das iniciativas de controle. Paranhos, por exemplo, comenta sobre o entrudo:

Fatal influência europeia! Perdemos a liberdade romana de que usávamos nestes dias, tornaram ilícitos os inocentes e antigos folguedos com que, quais doidos pacíficos e engraçados, nos despedíamos dos prazeres profanos para começarmos a vida de abstinência (...). É contrária aos hábitos da população brasileira, inimiga do bom gosto, ineficaz, e, portanto, tirânica e intolerável a lei que proíbe absolutamente as limonadas e as canecas de água cheirosa ${ }^{28}$.

O cronista capta as tensões do momento em que está mudando o perfil das festas momescas. No período realizar-se-á um evento que para muitos pesquisadores marcará o nascimento do carnaval moderno no país: $\mathrm{o}$ desfile do "Congresso das Summidades Carnavalescas" (1855), organizado de forma ordeira, um marco de um jeito burguês de conceber os festejos ${ }^{\text {aa }}$.

Outra grande polêmica do momento era o uso não controlado de fogos de artifício (bombas e buscapés), notadamente por ocasião dos festejos juninos. Otaviano não hesita em comparar, uma vez mais demonstrando como o esporte era compreendido como prática civilizada: "Há tanto divertimento digno de preferência e que não depõe contra a civilização! Os bailes, as regatas, as corridas, as digressões campestres, tudo isso é melhor do que estragar a água e a pólvora, constipando e queimando" 27 . Todavia, na mesma crônica, comenta com preocupação: "Aonde iríamos parar com esta maldita civilização que estraga tudo que tínhamos de tradicional e de poético. (...). Brevemente o governo se verá na necessidade de mandar recolher ao museu uma amostra de cada qual destas vítimas da civilização" ${ }^{27}$.

Mesmo que persistissem ambiguidades, naquele momento era unanimidade entre os cronistas investigados que o esporte era uma das práticas que contribuiria para o avanço dos costumes, inclusive por ser uma benfazeja influência dos países europeus. Ao comentar as corridas de cavalos realizadas em junho de 1854, Otaviano observa:

A feição desta semana é a anglomania. Tudo fala inglês, tudo arranha os termos britânicos, tudo cita os arestos do turfe do jockey-club. Aqui reclama-se pela necessidade de suavizar a curva do race-course, ali pede-se mais decência e decoração nos stands, acolá exige-se que os sportsmen depositem o valor de suas apostas; por toda a parte discute-se a vantagem de se instituir um Stud-Book para se registrar a vida e proezas de cada um dos cavalos generosos ${ }^{26}$.

Mais do que argumentos de natureza simbólica acerca da utilidade social do esporte, havia outros de ordem mais pragmática, como a contribuição que o turfe poderia dar para melhorar a performance dos cavalos brasileiros, um tema que sempre esteve presente nos discursos dos envolvidos com a prática. Por exemplo, assim se falou sobre a sua importância no Diário Fluminense de 1 de agosto de 1825: "Este divertimento, (...), pode ter um bom resultado para o Brasil, e vem a ser, que se nossos compatriotas com ele se entusiasmarem como fazem os ingleses, haverá mais cuidado do que agora sobre as raças de cavalos, objeto que nos tem sido até hoje indiferente"

Paranhos faz eco a tal aspecto ao observar os intuitos do Major Suckow ao arrendar o Prado do Club de Corridas: "nos assegura o utile dulce que reúne esse divertimento. É um meio de ir se cuidando no país do melhoramento da raça cavalar e de formar destros e intrépidos cavaleiros, do que tudo carecemos"18.

Esse tema vem à tona muitas vezes nos seus escritos, inclusive quando ironiza sua incapacidade de tomar parte plena na nova atividade:

$\mathrm{Eu}$, que bem sabe tive sempre presunção de destro cavaleiro, e que gosto de amansar com as minhas chilenas certos animais bravios, quando estou em terreno próprio, e sinto-me disposto para esses exercícios, que são úteis ao corpo, e de que muito depende o futuro da raça cavalar em nosso país, tinha mandado vir de Inglaterra um dos mais afamados racers para ir correr o páreo, não duvidando dar o mesmo preço por que 
outrora se vendeu o célebre corredor Eclipse. Mas como é mais que certo que não chegará no vapor de junho, pretendo ser mero espectador, montado no mais barato lazarento que por aí encontrar ${ }^{37}$.

$\mathrm{Na}$ fala de Paranhos há um interessante aspecto: a percepção de que o turfe também deveria ser encarado como um exercício "para o corpo", posição que antecipa em algumas décadas uma dimensão que estará explicita nos discursos sobre o remo identificáveis no final do século XIX. O cronista chega a sugerir que outros esportes fossem inseridos nos eventos turfísticos:

Seria para desejar que o divertimento não fosse exclusivamente equestre, que fosse entremeado de alguns exercícios no gênero dos jogos olímpicos ${ }^{\mathrm{ac}}$ ou que ao menos a música se mostrasse menos escassa e não se fizesse uma viagem ao Prado só para ver corridas como as que tem havido. Bem sei que para os amadores é isto bastante, e que é já por si um belo espetáculo gozar da linda perspectiva do Prado no meio de milhares de pessoas alegres e animadas. Mas estamos na época de progresso, os nossos gentlemen são muito comodistas, e o gosto pelo sport inglês ainda agora é que começa ${ }^{23}$.

Otaviano também encarava o esporte como uma forma de mobilizar a juventude. Como Paranhos, seus argumentos antecipam posições que se tornarão mais comuns na transição dos séculos XIX e XX: "A geração atual já nasceu raquítica: vive como os velhos que tiveram uma mocidade estagnada; vive efeminadamente, a excitar-se; joga o "lansquenet"ad, come ostras passadas por Vinho do Porto, lê alguma novela ou alguma poesia erótica"35. Vejamos como sua posição se aproxima a de um cronista que, nos anos iniciais do século XX, exaltava as contribuições do remo:

Essa geração, que está se educando no mar, face a face com o perigo, criando a energia muscular e energia moral, já é mais bela, mais forte, mais nobre do que a minha. Os adolescentes de hoje já não são como os de ontem, magros e tristes, macambúzios e histéricos, criados entre o rigor do carrancismo paterno e a brutalidade dos mestres boçais, entre sustos e palmadas, sem exercício físico e sem liberdade de espírito (...) os meninos de hoje já são bravos como homens ${ }^{38}$.

Otaviano estava seguro que os exercícios hípicos, notadamente as corridas ae ("a verdadeira escola do bom cavalheiro"), poderiam contribuir para o forjar de uma juventude mais altiva e ativa, de que tanto necessitava o país para garantir seu futuro: "O meneio do corpo, a prontidão e docilidade da rédea, a energia e vivacidade dos movimentos, o ânimo e o sangue-frio, são condiçôes mais favoráveis à vitória, do que as pontas suadas de um chicote ou a roseta ensanguentada de uma espora" 26 .

O cronista também não deixou passar despercebidas as possíveis contribuições econômicas do turfe. Para ele, as corridas, ao fazer cavalos se enfrentarem em uma competição pública, estimulava os criadores a investirem na criação de um animal nacional de qualidade:

Entrando agora em outra ordem de consideraçōes, cumpre observar que as corridas não se podem considerar apenas uma questão de luxo e de ostentação pública, nem mesmo um simples divertimento.

(...). Em suma, todos se esforçarão por apresentarem nas apostas os melhores bucéfalos e os mais velozes hipogrifos ${ }^{26}$.

No seu olhar, tratava-se de uma questão tão importante quanto as preocupaçóes com a agricultura e com a indústria. Conclama mesmo os ministérios, especialmente o da Guerra, a dedicar atenção ao tema. Chega a convocar: "É tempo de aproveitar-se a disposição dos ânimos para se instituir na corte uma sociedade promotora da equitação e do desenvolvimento da raça cavalar" 26 .

Com tanta vinculação com a política e a economia, não surpreende que já naquele momento os eventos esportivos comumente ganhassem ares patrióticos. Por exemplo, invariavelmente o início das provas de turfe e das regatas dava-se com o Hino Nacional executado por ocasião da chegada do Imperador. Mesmo que ainda timidamente, se começava a vincular o esporte à ideia de nação, uma noção que estava, inclusive, plenamente em construção no período ${ }^{\text {af15. }}$.

Depois dos momentos conflituosos que marcaram o pós-independência do Brasil, no início da segunda metade do século XIX, uma relativa estabilidade política e econômica gestou boas condições para que a nação avançasse em seu processo de consolidação ${ }^{5,15}$. Até mesmo por isso, tratou-se de um período de efervescência cultural, no qual se pode destacar a maior busca do espaço público como "lócus" de vivências sociais, a valorização da vida mundana.

Nesse cenário, surgiu um novo gênero literário, que ocupou espaço em uma imprensa que tentava conquistar mais leitores, garantir sua influência e sintonizar-se com as mudanças em curso: as crônicas, comumente publicadas na seção folhetim. Entre os temas abordados, havia uma novidade: o esporte, que anos 1850 dava passos mais significativos em direção a sua estruturação, sem ainda definitivamente consolidar-se.

O esporte, no olhar dos cronistas investigados, estava profundamente articulado com outras 
dimensões sociais de então, dramatizando projetos, propostas, conflitos e tensões. Importantes nomes da política nacional com ele estavam envolvidos. As mudanças econômicas se faziam sentir em seu âmbito e interferiam diretamente em sua conformação. Era uma expressão da valorização da diversão. Os problemas de uma cidade em mutação também nos eventos esportivos eram perceptíveis.
Nos olhares dos autores com os quais trabalhamos, o esporte tratava-se de uma diversão civilizada que poderia trazer muitas contribuições simbólicas e econômicas para a nação. Até mesmo por tal vinculação, suas crônicas também desempenharam uma função pedagógica ao esclarecer sobre as peculiaridades do que consideravam um avanço da vida social carioca, fluminense e nacional.

\section{Notas}

a. Periódico publicado no Rio de Janeiro entre os anos de 1830 e 1831.

b. Periódico publicado no Rio de Janeiro entre os anos de 1836 e 1837.

c. Para mais informações sobre a trajetória do folhetim, ver MEYER ${ }^{39}$.

d. Alguns exemplos: "Memórias de um sargento de milícias", de Manuel Antônio de Almeida, publicado, em 1852/1853, no Correio Mercantil; "A carteira de meu tio", de Joaquim Manuel Macedo, publicado, em 1855, em A Marmota Fluminense; "O Guarani”, de José de Alencar, publicado, em 1857, no Diário do Rio de Janeiro; "Mão e luva”, de Machado de Assis, publicado, em 1874, em O Globo.

e. Criado em 1827, tendo como foco as questôes da economia, paulatinamente foi mudando de perfil, passando também a se debruçar sobre a política e os assuntos mundanos. Foi um dos mais importantes jornais do Império. Para mais informaçôes, ver JunQUEIRA ${ }^{40}$.

f. Publicado de 1848 a 1868, ocupou espaço de importância no Segundo Reinado. Tinha um perfil político liberal e engajado, ao contrário do Jornal do Commercio que era mais moderado. Para mais informaçôes, ver RIBEIRO ${ }^{41}$.

g. Entre outros importantes cargos que ocupou, Paranhos foi presidente do Conselho de Ministros, de 1871 a 1875, quando também foi titular do Ministério da Fazenda. Foi ainda Ministro das Relaçôes Exteriores (1855-1857; 1858-1859), Ministro da Marinha (1853-1855; 1856-1857) e Ministro da Guerra (1871).

h. A série foi publicada até 28 de dezembro de 1851, sob responsabilidade, segundo sugere Rodrigues ${ }^{12}$, de Francisco Antônio Picot.

i. Foi como secretário de Honório Hermeto Carneiro Leão, que assumira a função de ministro na região do Rio da Prata.

j. Essa tese é defendida por Ewald ${ }^{42}$.

k. Diplomata, Otaviano foi um dos negociadores do Tratado da Tríplice Aliança. Foi Conselheiro do Imperador e Diretor da Instrução Pública.

1. Rocha já tinha experiência nos seguintes jornais: O Cronista, Correio Oficial, O Atalante, O Brasil, O Velho Brasil, O Correio do Brasil. Colaborava com o Jornal do Commercio desde a década de 1830.

m. Ao transferir-se para o Diário do Rio, em 1855, Alencar ainda publicou a série, no novo jornal, por mais dois meses.

$\mathrm{n}$. Deve-se ter em conta que esses dados eram uma estimativa. O primeiro censo oficial foi realizado em 1872 e apontou que o município da Corte tinha 226.033 habitantes livres e 48.939 escravos.

o. Na verdade, as diferenças entre os partidos não eram diametrais, ambos sendo representantes das elites. Para mais informações, ver CARVALHO ${ }^{4}$.

p. Para mais informações sobre os primeiros momentos do turfe, ver COSTA ${ }^{43}$, CARVALHO $^{44}$ e Melo ${ }^{45}$.

q. O próprio Paranhos chegou a ser sócio honorário do futuro Jockey Club (criado em 1868), já que era, na ocasião da fundação, presidente da Sociedade Auxiliadora da Indústria Nacional, que abrigou e apoiou a iniciativa.

r. Para mais informações sobre tal debate no decorrer do século XIX, ver MELO ${ }^{45}$.

s. Para mais informaçôes, ver Melo ${ }^{45}$.

t. Candido José de Carvalho era o proprietário do estabelecimento. Os ingressos custavam 600 réis para banhos durante o dia e 400 réis para banhos noturnos; crianças de 6 a 10 anos pagavam metade do valor. Era gratuita a entrada para os mais novos ${ }^{46}$.

u. Personagem importante do Império, na época era conselheiro, diplomata e presidente da Sociedade Auxiliadora da Indústria Nacional.

v. Havia muitos que assistiam às regatas de barcos fundeados na Baía de Guanabara. 
w. As regatas pouco apareceram nas crônicas de Otaviano. Na verdade, houve somente um evento náutico quando esteve à frente do "Folhetim do Jornal do Commercio", mais um indício de que não eram organizados com frequência.

x. O primeiro desafio mais divulgado no Rio de Janeiro foi realizado em 1846, na Praia de Santa Luzia, entre as canoas Lambe-Água e Cabocla, já contando com grande público na assistência. Para mais informaçôes, ver MelO ${ }^{45}$.

y. Um indício foi a grande difusão do relógio de algibeira, conhecido como "cebolão" ${ }^{47}$.

z. Para mais informaçôes, ver MeLO ${ }^{48 .}$

aa. Para mais informaçôes sobre o tema, ver FERREIRA ${ }^{49}$.

ab. Para mais informações sobre os debates acerca dos benefícios do turfe para os cavalos nacionais, ver MeLO ${ }^{45}$.

ac. Quando Paranhos escreveu essa crônica ainda não fora realizada a primeira edição dos Jogos Olímpicos modernos (1896). O autor referiu-se aos jogos gregos, certamente influenciado por uma releitura moderna do período clássico. Para mais informações, ver CANTARELA ${ }^{50}$.

ad. Trata-se de um jogo de cartas.

ae. Com isso, Otaviano sugeria que as corridas eram mais eficientes do que a equitação, na época considerada como importante ferramenta educacional por famílias das elites.

af. Essa relação entre esporte e nação somente no futuro ficará mais explícita, quando claramente a prática for mobilizada no âmbito dos discursos identitários nacionais. Para mais informações sobre o tema, ver HobSBAWM e RANGER ${ }^{51}$ e GUEDES $^{52}$.

\begin{abstract}
"We have lovers to the sea and to the land": representations of sport in feuillentons (Rio de Janeiro; 1851-1855)

Considering the relevance of the material published in the first Brazilian feuilletons, the aim of this study is to discuss the presence of the sport in Rio de Janeiro early years of the second half of the nineteenth century (1851-1855) from the representations of three pioneers of chronic Brazilian: José Maria Paranhos, Francisco Otaviano and José de Alencar. We were stimulated by some not casual coincidences: the initial moments of a practice, represented in the first moments of a literary genre, in a period when there was some political and economic stability, in which some groups began to aspire to adopt modern ideas.
\end{abstract}

KEY WORDS: Sport history; Literature; Press; Second Empire.

\title{
Referências
}

1. Melo VA. A crônica como fonte e o remo no Rio de Janeiro da transição do século XIX/XX. XI Congresso Brasileiro de Ciências do Esporte; 1999; Florianópolis, BR. Florianópolis: CBCE; 1999. [citado 20 dez. 2011]. Disponível em: http://www.sport.ifcs.ufrj.br/docs/producoes.html.

2. Melo VA. Dicionário do esporte no Brasil. Campinas: Autores Associados/CCS-UFRJ; 2007.

3. Lucena RF. A crônica como gênero que introduziu o esporte no Brasil. Rev Bras Ciênc Esporte. 2003;25:159-71, 2003.

4. Carvalho JM. A construção da ordem e o teatro das sombras. Rio de Janeiro: Civilização Brasileira; 2003.

5. Paula JA. O processo econômico. In: Carvalho JM, coordenador. História do Brasil Nação (1808-2010). Rio de Janeiro: Objetiva; 2012. v.2: A construção nacional (1830-1889). p.179-224.

6. Picot FA. Cartas ao amigo ausente. Jornal do Commercio. 3 nov. 1851:1.

7. Nóbrega MS. A criação do folhetim de imprensa no Brasil: os textos de Francisco Otaviano. VI Encontro Nacional da Rede Alfredo de Carvalho; 2008; Niterói, BR. Niterói: UFF, 2008. [citado 18 dez. 2011]. Disponível em: http:// paginas.ufrgs.br/alcar/encontros-nacionais-1/6o-encontro-2008-1.

8. Soares MVN. A crônica oitocentista: “Ao correr da pena”, de José de Alencar. XI Congresso Internacional da ABRALIC. 2008; São Paulo, BR. São Paulo: USP; 2008. [citado 22 dez. 2011]. Disponível em: http://www.abralic.org.br/anais/ cong2008/AnaisOnline/simposios/pdf/075/MARCUS_SOARES.pdf.

9. Nadaf YJ. O romance-folhetim francês no Brasil: um percurso histórico. Letras. 2009;19:119-38.

564 - Rev Bras Educ Fís Esporte, (São Paulo) 2013 Out-Dez; 27(4):553-66 
10. Souza SCM. Ao correr da pena: uma leitura dos folhetins de José de Alencar. In: Chalhoub S, Pereira LAM, organizadores. A história contada. Rio de Janeiro: Nova Fronteira; 1998. p.123-44.

11. Ipanema C. Folhetinistas: "A Semana”, de Francisco Otaviano. SBPH.XXV Reunião da SBPH; 2005; Curitiba, BR. Curitiba: SBPH; 2005. [citado 20 dez. 2011]. Disponível em: http://sbph.cliomatica.com/2005/cultura-e-suas-manifestacoes/cybelle-ipanema.

12. Rodrigues JH. Explicação. In: Paranhos JMS. Cartas ao amigo ausente. Rio de Janeiro: ABL; 2008. p.ix-xxxix.

13. Almanak Laemmert Rio de Janeiro: Tipografia Universal, 1852. (Almanak administrativo, mercantil, e industrial do Rio de Janeiro).

14. Bosi A. Cultura. In: Carvalho JM, coordenador. História do Brasil Nação (1808-2010). Rio de Janeiro: Objetiva; 2012. v.2: A construção nacional (1830-1889). p.225-80.

15. Carvalho JM. A vida política. In: Carvalho JM, coordenador. História do Brasil Nação (1808-2010). Rio de Janeiro: Objetiva; 2012. v.2: A construção nacional (1830-1889). p.83-130.

16. Ewald A. Sartre, Simmel e uma "fenomenologia social" das crônicas folhetinescas. Sens-public, 2005. [citado em 20 dez 2011]. Disponível em: http://www.sens-public.org/article.php3?id_article=156.

17. Alencar JM. Ao correr da pena. Correio Mercantil. 24 set. 1854:2.

18. Paranhos JMS. Cartas ao amigo ausente. Jornal do Commercio. 23 mar. 1851:1.

19. Paranhos JMS. Cartas ao amigo ausente. Jornal do Commercio. 24 maio 1851:1.

20. Paranhos JMS. Cartas ao amigo ausente. Jornal do Commercio. 1 jun. 1851:1.

21. Paranhos JMS. Cartas ao amigo ausente. Jornal do Commercio. 8 jun. 1851:1.

22. Paranhos JMS. Cartas ao amigo ausente. Jornal do Commercio. 16 jun. 1851:1.

23. Paranhos JMS. Cartas ao amigo ausente. Jornal do Commercio. 21 set. 1851:1.

24. Needell JD. Belle époque tropical. São Paulo: Companhia das Letras; 1993.

25. Otaviano F. A semana. Jornal do Commercio. 11 dez. 1851:1.

26. Otaviano F. A semana. Jornal do Commercio. 11 jun. 1854:1.

27. Otaviano F. A semana. Jornal do Commercio. 4 jun. 1854:1.

28. Paranhos JMS. Cartas ao amigo ausente. Jornal do Commercio. 2 mar. 1851:1.

29. Rocha JJ. A semana. Jornal do Commercio. 20 maio 1855:1.

30. Alencar JM. Ao correr da pena. Correio Mercantil. 22 abr.1855:2.

31. Alencar JM. Ao correr da pena. Correio Mercantil,. 27 maio 1855:2.

32. Alencar JM. Ao correr da pena. Correio Mercantil. 1 out. 1854:2.

33. Paranhos JMS. Cartas ao amigo ausente. Jornal do Commercio 24 fev. 1851:1.

34. Paranhos JMS. Cartas ao amigo ausente. Jornal do Commercio. 31 maio 1851:1.

35. Otaviano F. A semana. Jornal do Commercio. 2 out. 1853:1.

36. Otaviano F. A semana. Jornal do Commercio. 11 dez. 1853:1.

37. Paranhos JMS. Cartas ao amigo ausente. Jornal do Commercio. 18 maio 1851:1.

38. X. A cidade. A Canoagem. 1903;1:5.

39. Meyer M. Folhetim: uma história. São Paulo: Companhia das Letras; 1996.

40. Junqueira JR. Jornal do Commercio: cronista da história do Brasil em 1922. 2010 [dissertação]. Rio de Janeiro (RJ): Universidade do Estado do Rio de Janeiro, Instituto de Filosofia e Ciências Humanas; 2010.

41. Ribeiro JA. Correio Mercantil do Rio de Janeiro: modos jornalísticos e literários de composição. XXVIII Congresso Brasileiro de Ciências da Comunicação; 2005; Rio de Janeiro, BR. Rio de Janeiro: Intercom; 2005. [citado 20 dez. 2011]. Disponível em: http://www.portcom.intercom.org.br/novosite/pdfs/52299316788677491622775106705398388218.

42. Ewald AP. Fragmentos da modernidade nas crônicas folhetinescas do Segundo Reinado [tese]. Rio de Janeiro (RJ): Universidade Federal do Rio de Janeiro, Escola de Comunicação; 2000.

43. Costa C. O turfe de outrora. Rio de Janeiro: Vida Turfista; 1961.

44. Carvalho NOR, editor. Jockey Club Brasileiro: 130 anos. Rio de Janeiro: um século e meio de turfe. Rio de Janeiro: Imprinta; 1998. 45. Melo VA. Cidade sportiva: primórdios do esporte no Rio de Janeiro. Rio de Janeiro: Relume Dumará/FAPERJ; 2001.

46. Almanak Laemmert. Rio de Janeiro: Tipografia Universal; 1851. (Almanak administrativo, mercantil, e industrial do Rio de Janeiro).

47. Alencastro LF. Vida privada e ordem privada no Império. In: Alencastro LF, organizador. História da vida privada no Brasil 2a ed. São Paulo: Companhia das Letras; 1997. p.11-94.

48. Melo VA. Mulheres em movimento: a presença feminina nos primórdios do esporte na cidade do Rio de Janeiro (século XIX-primeira década do século XX). Rev Bras História. 2007;27:127-52. [citado 10 maio 2009]. Disponível em: http://www.scielo.br/pdf/rbh/v27n54/a08v2754.pdf. 
49. Ferreira F. O triunfal passeio do "Congresso das Summidades Carnavalescas" e a fundação do carnaval moderno no Brasil. Terceira Margem. 2006;10:11-26.

50. Cantarela E. El peso de Roma en la cultura europea. Madrid: Akal; 1996.

51. Hobsbawm E, Ranger T. A invenção das tradições. São Paulo: Paz e Terra; 1997.

52. Guedes SL. Futebol e identidade nacional: reflexões sobre o Brasil. In: Priore M, Melo VA, organizadores. História do esporte no Brasil: do Império aos dias atuais. São Paulo: UNESP; 2009. p.453-80.

\begin{tabular}{r|r} 
ENDEREÇO & \\
Victor Andrade Melo & \\
Universidade Federal do Rio de Janeiro & $\begin{array}{r}\text { Recebido para publicação: 30/12/2012 } \\
\text { Av. Pedro Calmon, 550 } \\
\text { Revisado: 17/04/2013 } \\
\text { Aceito: 24/04/2013 } \\
\text { e-mail: victor.a.melo@uol.com }\end{array}$ \\
& \\
\hline
\end{tabular}

